\title{
EVALUACIÓN DEL CULTIVO PROTEGIDO POR AGROTEXTIL EN LA CULTURA DE LECHUGA Y SU DESEMPEÑO EN DIFERENTES TIPOS DE APLICACIONES
}

\author{
F.J.S. Salas, C.A.P. Moraes, S. Garcia*, T.T. Sabundjian
}

Instituto Biológico, Centro de Pesquisa e Desenvolvimento de Sanidade Vegetal, Av. Cons. Rodrigues Alves, 1.252, CEP 04014-002, São Paulo, SP, Brasil. E-mail: salas@biologico.sp.gov.br

\section{RESUMEN}

EVALUACIÓN DEL CULTIVO PROTEGIDO POR AGROTEXTIL EN EL CULTIVO DE LECHUGA Y SU RENDIMIENTO EN DIFERENTES APLICACIONES. El uso de cultivos protegidos con agrotextil es una técnica que se ha ido destacando a lo largo del tiempo, por su eficacia y facilidad de aplicación, principalmente en forma de cubiertas flotantes. El objetivo de este trabajo fue evaluar los diferentes métodos de aplicación del agrotextil blanco (17 g / m2) aplicado en forma de coberturas flotantes, asociadas a cubierturas de suelo utilizando agrotextil negro (45 g / m2) y mulching plástico negro (MP $25 \mu \mathrm{m}$ ) en el cultivo de lechuga. Los resultados mostraron variaciones significativas para masa fresca, lo que indica que el mejor método de aplicación fue en mulching plástico asociado al agrotextil en forma de cubierta flotante. El cultivo de lechuga mantenida sobre el agrotextil mostró un desarrollo vegetativo superior cuando se comparó en la parte aérea el número de hojas / planta y la altura, mostrando mejores resultados cuando se utilizó, en el tratamiento, la cobertura directamente sobre el cultivo o utilizando una guía de hilo de nylon como guía en comparación con el tratamiento sin cobertura agrotextil. Otro factor positivo fue el efecto de agrotextil como barrera física contra insectos plaga, reduciendo significativamente la infestación.

PALABRAS CLAVE: Lactuca sativa, barreras físicas, ambiente protegido, insectos plaga.

RESUMO

AVALIAÇÃO DO CULTIVO PROTEGIDO POR AGROTEXTIL NA CULTURA DA ALFACE E SEU DESEMPENHO EM DIFERENTES APLICAÇÕES. A utilização do cultivo protegido com agrotextil é uma técnica que vem se destacando ao longo do tempo, por sua eficiência e facilidade de manejo, principalmente na forma de cobertura flutuante. O objetivo do presente trabalho foi avaliar os diferentes métodos de aplicação do agrotextil branco $\left(17 \mathrm{~g} / \mathrm{m}^{2}\right)$ aplicado na forma de cobertas flutuantes, associado a coberturas de solo utilizando o agrotextil negro $\left(45 \mathrm{~g} / \mathrm{m}^{2}\right)$ e o mulching plástico preto (MP $25 \mu \mathrm{m}$ ) na cultura de alface. Os resultados mostraram variações significativas quanto à massa fresca, indicando que o melhor método de aplicação se constituiu no mulching plástico associado ao agrotextil na forma de coberta flutuante. A cultura da alface mantida sobre o agrotextil mostrou um desenvolvimento vegetativo superior quando se comparou o número de folhas/ planta e a altura da parte aérea, apresentando melhores resultados quando se utilizou, no tratamento, a cobertura diretamente sobre o cultivo ou empregando um fio guia quando comparados ao tratamento sem cobertura de agrotextil. Outro fator positivo foi o efeito do agrotextil como barreira física contra insetos-praga reduzindo significativamente a infestação.

PALAVRAS-CHAVE: Lactuca sativa, barreiras físicas, ambiente protegido, insetos-praga.

\section{INTRODUCCIÓN}

La busca por alimentos más sanos y la preocupación con el medioambiente en los últimos años han modificado significativamente la forma de cultivo y el manejo de algunos sectores de producción de hortalizas. En este sentido, se nota en diferentes regiones de Brasil, el empleo de nuevas tecnologías para la optimización de su producción, siendo el cultivo protegido, asociado a otras técnicas, una realidad eficaz y rentable (NASCIMENTO, 2004).

La utilización del cultivo protegido con agrotextil es una técnica que viene destacándose a lo largo del tiempo, por su eficiencia y facilidad de manejo, siendo quela principal forma de aplicación és comocubiertas (mantas) flotantes, que se implantan sobre la cultura.

\footnotetext{
*Bolsista PIBIC/CNPq.
} 
Algunos estudios realizados en Brasil confirman la eficacia del producto agrotextil blanco en el aumento de producción, mejora de calidad del producto, bien como en el control de insectos. Estas ventajas fueron observadas en el cultivo de fresas (Отто et al., 2000), pak choi (REgHIN et al., 2001), lechuga americana en las estaciones de otoño y invierno (TuPICH et al., 2001) y en verano y primavera (PADILHA etal., 2001a; PADILHA etal., 2001b). En el cultivo de arracacha, el uso del agrotextil aumentó el enraizamiento de las mudas y anticipó la época de trasplante (REGHIN et al., 2000).

Factores bióticos comola ocurrencia deinnúmeros insectos pueden perjudicar el cultivo de hortícolas, causando daños directos e indirectos. Se destacan por ocasionar daños más frecuentes en el cultivo de lechuga, en las áreas productoras de São Paulo, los afídios (Hyperomyzus lactucae, Myzus persicae, Uroleucum ambrosiae e Macrosiphum euphorbiae), mosca minadora (Lyriomiza spp.) y "patriota o brasileiriño" (Diabrotica speciosa), entre otros (GALLO et al., 1988).

Las técnicas adoptadas para el control de los insectos, en cultivos de importancia económica, muchas veces pueden elevar el uso de defensivos causando daños al agro ecosistema y a la salud pública. Con esto, la utilización de agrotextil en las culturas de mayor incidencia de plagas, se transformó en una técnica adoptada por los productores que pretenden alcanzar un control eficaz y reducción en la aplicación de defensivos. De acuerdo con SALAS (2004), el empleo de agrotextil en el cultivo de papa semilla se demostró eficaz hasta los 45 días de aplicación, obteniendo una reducción en la aplicación de insecticidas cuando comparada al método de plantío convencional. Uno de los destaques de esta técnica es el aumento del crecimiento vegetativo delas plantas cultivadas sobre el material, resultando en la formación de masa verde precozmente y amenizando las fases mas críticas de la infección por virus, gracias a la reducción de insectos vectores amenizando el surgimiento de resistencia de estos organismos a insecticidas y auxiliando en el equilibrio del agro ecosistema.

Diversos métodos fueron desarrollados para realizar el control de malas hierbas, entre ellos se destaca la cubierta de suelo, mas conocida como mulching. Esta tecnica consiste en la aplicación de cualquier cubierta en la superficie del suelo, actuando como barrera física a la luz solar y vapor de agua entre el suelo y la atmósfera. Para el revestimiento del área de plantío se puede utilizar polietileno (plástico), material vegetal (paja ocáscaras decereales) o polipropileno (agrotextil). La utilización de mulching en la agricultura viene creciendo diariamente, siendo utilizado para la reducción de la evaporación y como consecuencia aumentar la conservación de humedad del suelo y control de malas hierbas. En Brasil, la primera cultura donde se empleó el sistema demulching fue la cultura do fresas (Gото, 1997). Reghin et al. (2002) notaron que la utilización del agrotextil blanco aumentoel desenvolvimiento demalas hierbas, debido a la mejora de las condiciones ambientales, imposibilitando su uso en áreas de gran incidencia de estas plantas. La técnica de cubierta de suelo con agrotextil negro en la cultura de lechuga se demostró eficiente en el control de malas hierbas, promoviendo un aumento de $22,21 \%$ en la masa fresca cuando comparado con la cubierta de suelo con paja de arroz (REGHIN et al., 2002).

El presente trabajo tuvo como principal objetivo estudiar los diferentes métodos de aplicación del cultivo protegido con agrotextil blanco $\left(17 \mathrm{~g} / \mathrm{m}^{2}\right)$ asociado al revestimiento de suelo empleando agrotextil negro $\left(45 \mathrm{~g} / \mathrm{m}^{2}\right)$ y mulching plástico negro (MP $25 \mu \mathrm{m}$ ) en la cultura de la lechuga.

\section{MATERIAL Y MÉTODOS}

El experimento fue realizado en el Municipio de Jarinu, región productora de hortícolas, localizada en el cinturón verde de São Paulo, Brasil $\left(23^{\circ} 02^{\prime} 26,18^{\prime \prime}\right.$ Sur / 46³9'07,77" Oeste, $755 \mathrm{~m}$ de altitud), en el periodo de junio/2005 con temperaturas médias que variaron entre 16 a $24^{\circ} \mathrm{C}$. Las plantas fueron sometidas a riego con aspersores mobiles rotatorios 2 vezes al dia por periodos de 15 minutos. Para obtener mayor uniformidad en los riegos entre los tratamientos se emplearon boquillas de control de aire. El delineamiento experimental se constituyo de 18 bloques al acaso, midiendo $48 \mathrm{~m}^{2}$ cada, divididos en 6 tratamientos: i) sin protección agrotextil + mulching; ii) sin protección agrotextil + mulching agrotextil; iii) protección agrotextil cubierta flotante + mulching; iv) protección agrotextil - cubierta flotante + mulching agrotextil; v) protección agrotextil - hilo guía + mulching; vi) protección agrotextil - hilo guía + mulching agrotextil, con 3 repeticiones cada.

Elcultivar evaluadofue Lechuga Crespa Hortência. Posteriormente a la plantación en bandejas de 200 alvéolos, las plántulas fueron multiplicadas en el estadio de 2-3 hojas definitivas, en caballones previamente cubiertos con mulching plástico o agrotextil. Durante el crecimiento vegetativo de las plantas se aplicó abono nitrogenado de cobertura para todos los tratamientos (7 y 14 DPT - días posteriores al trasplante). Después de la eliminación de malas hierbas, en cada parcela fueron instaladas trampas amarillas atractivas del tipo bandeja de agua, para monitoreo delos insectos en todos los tratamientos. Al centrodelexperimento fueroninstaladas tres trampas 
atractivas verdes para evaluar insectos colonizadores presentes en elárea experimental. Posteriormente, se implantó el sistema de cultivo protegido con agrotextil (tela hidrofílica de polipropileno expandido con $17 \mathrm{~g} / \mathrm{cm}^{2}, 85 \%$ de transparencia de luz) empleando dos métodos: i) cubierta flotante, sobre la cultura, sin emplear ninguna estructura de sustentación y, ii) cubierta guiada con hilo de nylon con altura media de $45 \mathrm{~cm}$ del suelo.

Para a evaluar la entomofauna, se realizaron colectas semanales de las trampas, que fueron transportadas al Laboratório de Fitovirologia y Fisiopatologia (LFF) del Centro de Pesquisa y Desarrollo en Sanidad Vegetal (CPDSV) del Instituto Biológico (IB) para identificación y conteo de las especies dominantes hasta el periodo de la cosecha. Para determinar las características de producción fueron colectadas, a los $45 \mathrm{DPT}$, cuatro plantas por parcela al acaso, donde se determinó: número total de hojas/planta, altura de la parte aérea, masa fresca de la parte aérea y masa seca. Las evaluaciones realizadas semanalmente y los datos de las medias totales obtenidas fueron sometidos a análisis de variancia por el test de Tukey (ANOVA) a nivel de 5\% de probabilidad.

\section{RESULTADOS Y DISCUSIÓN}

Los resultados mostraron quela mejor combinación entre las formas de cultivo protegido evaluadas fue obtenida cuando se utilizó el plástico como cubierta de sueloy el agrotextil en la forma decubierta flotante, que cuando combinados, resultaron en la máxima producción de massa fresca de la parte aérea, 436,66 $\mathrm{g} /$ planta $^{-1}$ (Tabla 1 ).

Analizando la masa fresca $(\mathrm{g})$ de la parte aérea de las plantas entre las diferentes combinaciones de cubierta de suelo + cultivo protegido por agrotextil, se observó una diferencia significativa cuando se comparó con el cultivo testigo (sin cubierta), resultando en mayor desarrollo de las plantas cuando sometidas al tratamiento con agrotextil, independientemente de la forma de aplicación del material (Tabla 1).

Relatos anteriores demostraron que plantas cultivadas sobre mulching plástico y bajocultivo protegido con agrotextil obtuvieron mayor masa fresca (LAMONT, 1993; PEREIRA et al., 2000; HANADA, 2001).

Cuanto a la característica masa seca (g) no hubo diferencia significativa cuando se compararón los tratamientos. Resultados semejantes a los encontrados fueron obtenidos anteriormente por REGHIN et al. (2002), que al analizar la masa seca de plantas herbáceas dicotiledóneas, que se desenvolvieron durante experimento realizado bajo agrotextil, en cultura de lechuga, también no evidenciaron diferencia significativa. Los autores justifican tal echo gracias a la supresión y por el crecimiento etiolado bajo condiciones de cubierta de suelo, resultando en la incapacidad de acumulo de masa seca.

Tabla 1 - Análisis estadística de la masa fresca (g) de la parte aérea de lechuga crespa cv. Hortência, entre los tratamientos de cubierta de suelo y cultivo protegido.

\begin{tabular}{lcccc}
\hline Tipo de cubierta de suelo & Cultivo protegido (flotante) & Cultivo protegido (guiado) & Sin cubierta & Média* \\
\hline Plástico & 436,66 & 408,33 & 337,50 & $394,16 \mathrm{a}$ \\
Agrotextil negro & 358,33 & 375,00 & 403,33 & $378,88 \mathrm{ab}$ \\
\hline Media* & $397,49 \mathrm{~A}$ & $391,66 \mathrm{AB}$ & $370,41 \mathrm{~B}$ & \\
\hline
\end{tabular}

*Medias seguidas por la misma letra mayúscula en la línea y minúscula en la columna, no son significativamente diferentes entre si a nivel de $5 \%$ de probabilidad, por el test de Tukey.

Tabla 2 - Análisis estadística del número total de hojas de lechuga crespa cv. Hortência entre los tratamientos de cubierta de suelo y cultivo protegido (flotante y guiado).

\begin{tabular}{lcccc}
\hline Tipo de cubiertade suelo & Cultivo protegido (flotante) & Cultivo protegido (guiado) & Sin cubierta & Média* \\
\hline Plástico & 26,00 & 24,50 & 19,33 & $23,27 \mathrm{a}$ \\
Agrotextil & 23,73 & 23,83 & 21,16 & $22,90 \mathrm{a}$ \\
\hline Media* $^{*}$ & $24,86 \mathrm{~A}$ & $24,16 \mathrm{~A}$ & $20,24 \mathrm{AB}$ & \\
\hline
\end{tabular}

*Medias seguidas por la misma letra mayúscula en la línea y minúscula en la columna, no son significativamente diferentes entre si a nivel de $5 \%$ de probabilidad, por el test de Tukey. 
Tabla 3 - Análisis estadística de la altura $(\mathrm{cm})$ de la parte aérea de lechuga crespa, cv. Hortência entre los tratamientos de cubierta de suelo y cultivo protegido.

\begin{tabular}{lcccc}
\hline Tipo de cubierta de suelo & Cultivo protegido (flotante) & Cultivo protegido (guiado) & Sin cubierta & Média* \\
\hline Plástico & 27,66 & 30,16 & 23,83 & 27,21 a \\
Agrotextil & 27,36 & 29,83 & 23,90 & 27,03 a \\
\hline Media* & $27,51 \mathrm{~A}$ & $29,99 \mathrm{~B}$ & $23,86 \mathrm{C}$ & \\
\hline
\end{tabular}

*Medias seguidas por la misma letra mayúscula en la línea y minúscula en la columna, no son significativamente diferentes entre si a nivel de $5 \%$ de probabilidad, por el test de Tukey.

Tabla 4 - Análisis estadístico de la reducción de insectos plaga, sobre cultivo de lechuga crespa cv. Hortência entre los tratamientos con y sin protección por agrotextil.

\begin{tabular}{lcc}
\hline & Percentage de eficácia como barrera física de insectos & \\
\hline Insectos colectados & Cultivo protegido (agrotextil) & Sin cubierta (testigo) \\
\hline Afídios & $76,25 \mathrm{a}$ & $23,75 \mathrm{~b}$ \\
Mosca minadora & $86,70 \mathrm{a}$ & $13,30 \mathrm{~b}$ \\
\hline
\end{tabular}

*Medias seguidas por la misma letra minúscula en la línea, no son significativamente diferentes entre si a nivel de $5 \%$ de probabilidad, por el test de Tukey.

El plantio bajo agrotextil de lechuga crespa mostró un desarrollo vegetativo superior, tanto en la característica número de hojas/ planta (24,86 y 24,16 número hojas/ planta) cuando comparado al tratamiento sin cultivo protegido (20,24 número hojas/planta) (Tabla 2), así como con la altura de la parte aérea, donde se obtuvieron resultados superiores para el tratamiento empleando cubierta flotante $(27,51 \mathrm{~cm})$, como en la que utilizó el hilo guía $(29,99 \mathrm{~cm})$ cuando comparados con el tratamiento sin cubierta $(23,86 \mathrm{~cm})$ (Tabla 3$)$.

Posiblemente, estos resultados se deben al microclima generado por el agrotextil, donde la temperatura se mantiene sin grandes variaciones, resultando en precocidad de la cosecha. Este hecho ya había sido anteriormente relatado por FELTRIM et al., (2003) en dos diferentes cultivares de lechuga.

Se notó que en el tratamiento con cultivo protegido guiado ocurrió mayor desarrollo en altura $(\mathrm{cm})$ de la parte área de la planta. Los números obtenidos pueden ser resultantes de la distancia ejercida por el hilo de nylonfijadoa unaaltura media de $45 \mathrm{~cm}$, loqueimpediría el contacto físico entreel agrotextil y la planta, facilitando su crecimiento y la reducción de daños. Sin embargo, no se notó diferencia significativa cuando se comparó los tratamientos de cubierta de suelo (mulching) entre el plástico y el agrotextil. Actualmente, el empleo del agrotextil en Brasil, tiene como principal enfoque el control de malas hierbas, hecho constatado en algunos experimentos utilizando agrotextil negro (cubierta de suelo) en la cultura de pak choi (REGHIN et al., 2001) y en el cultivo de lechuga cv. Veneza Roxa (REGHIN et al.,2002) y también como protección contra geladas. En el presente estudionoseobservóelsurgimientodemalashierbasen ningún tratamiento (datos no presentes), posiblemente por el control sucesivo con herbicidas y manejos culturales semanales.

El agrotextil demostró características deseables, tales como, resistencia física, porosidad, permeabilidad alcambiodegasesyagua,incrementandolautilización de riego por aspersión. Esto produjo entre otros aspectos observados la anticipación de la cosecha y un lote homogenizado. Por otrolado, la utilización del mulching plástico se mostró más eficiente en sistemas de riego porgoteo por elecho de ser impermeabley debidoa esto, permitir mayor provecho tanto de los insumos agrícolas como de la agua.

Otro factor positivo fue la constatación del efecto del agrotextil (cubierta flotante) como barrera física contra insectos plaga donde se observó una reducción de $76,25 \%$ de el número total de afídios alados y de 86,7\% de moscas-minadoras (Liriomyza spp.) cuando se compararon con la parcela testigo (Tabla 4) (Fig. 1). Se constató que los afídios predominantes en el área experimental fueron M.persicaey Hyperomyzuslactucae.

Diversos autores describen que el uso de cultivos protegidos por agrotextil reduzen la incidencia de afídios desde que previamente a la instalación sea realizada una aplicación con insecticidas, visando la(s) plaga(s) llave, de acuerdo a la cultura, como ocurre em pimentón (Avilla et al., 1995) y lechuga y brócoli (NEBREDA, 2005) e incluso del aparecimiento de enfermedades, principlamente de las que dependen de insectos-vectores como los fitovírus, especialmente los de transmisión no-persistente visto la dificultad del control con insecticidas (Fereres, 2000; HoOKs; FERERES, 2006). 


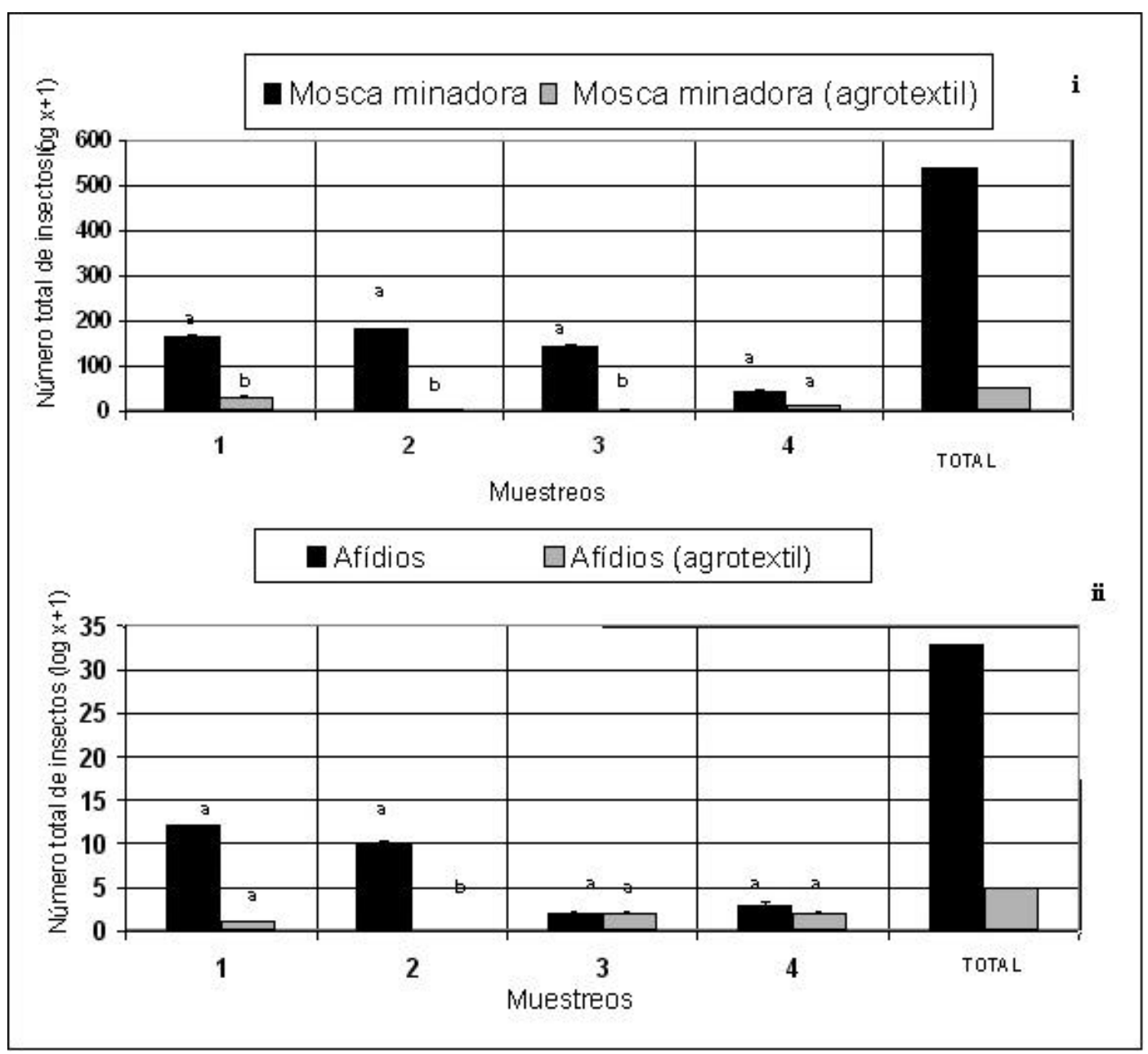

*Números en el mismo tratamiento seguidos de letras diferentes poseen diferencias significativas $(\mathrm{P}<0,05)$ segundo el test de Tuckey.

Fig. 1 - Número medio de mosca minadora (i) y de afídios (ii) colectados en campo experimental, Jarinu, SP, 2006.

De esta foma, reforzado por los resultados obtenidos, el empléo de barreras flotantes del tipo agrotextil se constituye en un método que puede optimizar la producción y también el control de plagas, reduciendo insectos que pueden prejudicar, incluso en índices elevados, la produccion de hortícolas de hojas, entre ellas la lechuga. Otros aspectos que se suman son la facilidad de aplicación, el bajo costo cuando comparado a plantios convencionales que realizan tratamientos periodicos con insecticidas, el bajo impacto con el medioambiente y la producción de alimentos más sanos.

\section{CONCLUSIONES}

Los mejores resultadosfueronobtenidoscuandose empleolacombinaciónmulching plásticocomocubierta de sueloy el agrotextil como cubierta flotante. También se puede afirmar que los resultados obtenidos indican que la utilización del agrotextil, puede reducir significativamente la incidencia de insectos plaga en la cultura de lechuga, transformándose en una alternativa viable y barata de control, incluso en la reducción de potenciales vectores defitovirus eincluso en reducción del número de aplicaciones con agroquimicos.

\section{REFERENCIAS}

AVILLA, C. Desarrollo de un programa de control integrado de virus transmitidos por pulgones en cultivo de pimiento (Capsicum annuum L.) al aire libre. 1995. 208P. Tesis (Doctorado) - Universidad Politécnica de Madrid, Madrid, 1995.

FERERES, A. Barrier crops as a cultural control measure of non-persistently transmitted viruses. Virus Research, v.71, p.221-231, 2000. 
FELTRIM A. L.; REGHIN. M.Y.; VINNE. J. Cultivo da Alface com agrotextil em diferentes períodos. Piblicatio UEPG: Ciencias Exatas e da Terra, Ciências Agrarias e Engenharia, Ponta Grossa, v.9, n.1, p.21 -27, 2003.

HANADA, T. The effect of mulching and row covers on vegetable production. Food and Fertilizer technology center, p.1-23, 2001. Disponível em: <http://www. agnet.org/library/abstract/eb332.html>. Acesso em: 25 mar. 2002

HOOKS, C.R.R.; FERERES, A. Protecting crops from non-persistently aphid-transmitted viruses: A review on the use of barrier plants as a management tool. Virus Research v.120, p.1-16, 2006.

GALLO, D.; NAKANO, O.; SILVEIRA NETO, S.; CARVALHO, R.P.L.; BATISTA, G.C. DE; BERTI FILHO, E.; PARRA, J.R.P.; ZUCCHI, R.A.; ALVES, S.B.; VENDRAMIM, J.D. Manual de entomologia agrícola. Piracicaba: Ed. Agronômica Ceres, 1988. 649p.

GOTO, R. Plasticultura nos trópicos: uma avaliação técnico-econômica. Horticultura Brasileira, v.15, p.163165, 1997. Suplemento.

LAMONT JUNIOR, W.J. Plastic mulches for the production of vegetable crops. Hort Technology, v.3, n.1, p.35-39, 1993.

NASCIMENTO, W.M. Novos rumos na produção de hortaliças. EMBRAPA Hortaliças, 2004. Disponível em: <http://www.cnph.embrapa.br/public/textos>. Acesso em: 15 abr. 2005

NEBREDA, M. Dinámica poblacional de insectos homópteros en cultivos de lechuga y bróculi, identificación de parasitoides asociados y evaluación de alternativas físicas de control. 2005. 227p. Tesis (Doctorado) - Universidad Complutense de Madrid, Madrid, 2005.

OTTO, R.F.; REGHIN, M.Y.; TIMÓTEO, P.; PEREIRA, A.V.; MADUREIRA, A. Resposta produtiva de duas cultivares de morango cultivadas sob "não tecido" de polipropileno no município de Ponta Grossa-PR. Horticultura Brasileira, v.18, p.210-211, 2000. Suplemento.

PADILHA, J.M.; TUPICH, F.L.B.; REGHIN, M.Y. Cultivo protegido de alface americana. IV. Estação de Primavera. In: ENCONTRO DE INICIAÇÃO CIENTÍFICA, 10., 2001, Ponta Grossa , PR. Anais. Ponta Grossa: Universidade Estadual de Ponta Grossa, 2001a. p.168.
PADILHA, J.M.; TUPICH, F.L.B.; REGHIN, M.Y. Cultivo protegido de alface americana. IV. Estação de Verão. In: ENCONTRO DE INICIAÇÃO CIENTÍFICA, 10., 2001, Ponta Grossa, PR. Anais. Ponta Grossa: Universidade Estadual de Ponta Grossa, 2001b. p.169.

PEREIRA, C.Z.; RODRIGUES, D.S.; GOTO, R. Ocorrência de plantas daninhas na cultura da alface em diferentes tipos de cobertura de solo no verão. Horticultura Brasileira, v.18, p.489-490, 2000. Suplemento.

REGHIN, M.Y.; OTTO, R.F.; SILVA, J.B.C. da. "Stimulate Mo" e proteção com “Tecido não Tecido" no pré-enraizamento de mudas de mandioquinhasalsa. Horticultura Brasileira, v.18, n.1, p.53-57, 2000.

REGHIN, M.Y.; OTTO, R.F.; van der VINNE, J.; FELTRIN, A.L. Produção de pak choi sob proteção com "não tecido" de polipropileno. Horticultura Brasileira, v.19, n.2, p.248, 2001. Resumo.

REGHIN, M.Y.; DALLA PRIA, M.; FELTRIN, A.L.; van der VINNE, J. Efeito da cobertura do solo e proteção das plantas de pak choi cultivadas com "não tecido" de polipropileno na ocorrência de doenças. Horticultura Brasileira, v.19, n.2, p.266, 2001. Resumo.

REGHIN, M.Y.; PURISSIMO, C.; FELTRIN, A.L.; FOLTRAN, M.A. Produção de alface utilizando cobertura do solo e proteção das plantas. Scientia Agraria, v.3, n.1/2, p.69-77, 2002.

SALAS, F.J.S. Comportamento de Myzus persicae e transmissão de estirpes de Potato virus Y (PVY) em diferentes cultivares de batata. 2004. 145p. Tese (Doutorado) - Escola Superior de Agricultura "Luiz de Queiroz", Universidade de São Paulo, Piracicaba, 2004.

TUPICH, F.L.B.; PADILHA, J.M.; REGHIN, M.Y. Cultivo protegido de alface americana. IV. Estação de Outono. In: ENCONTRO DE INICIAÇÃO CIENTÍFICA, 10., 2001, Ponta Grossa, PR. Anais. Ponta Grossa: Universidade Estadual de Ponta Grossa, 2001. p.178.

TUPICH, F.L.B.; PADILHA, J.M.; REGHIN, M.Y. Cultivo protegido de alface americana. IV. Estação de Inverno. In: ENCONTRO DE INICIAÇÃO CIENTÍFICA, 10., 2001, Ponta Grossa, PR. Anais. Ponta Grossa: Universidade Estadual de Ponta Grossa, 2001. p.179.

Recebido em 10/8/07

Aceito em 1/12/08 